\title{
Stripping Voltammetric Determination of Analgesics in Their Pharmaceuticals Using Nano-Riboflavin-Modified Glassy Carbon Electrode
}

\author{
Gopalakrishnan Gopu, ${ }^{1}$ Paramasivam Manisankar, ${ }^{1}$ \\ Baladhandapani Muralidharan, ${ }^{2}$ and Chinnapiyan Vedhi $^{3}$ \\ ${ }^{1}$ Department of Industrial Chemistry, Alagappa University, Karaikudi 630 003, Tamilnadu, India \\ ${ }^{2}$ Department of Chemistry, Birla Institute of Technology and Science-Pilani, P.O. Box 345055, Dubai, UAE \\ ${ }^{3}$ Department of Chemistry, V.O. Chidambaram College, Tuticorin 628 008, Tamilnadu, India
}

Correspondence should be addressed to Gopalakrishnan Gopu, nggopi79@yahoo.com

Received 3 March 2011; Accepted 15 April 2011

Academic Editor: Boniface Kokoh

Copyright (C) 2011 Gopalakrishnan Gopu et al. This is an open access article distributed under the Creative Commons Attribution License, which permits unrestricted use, distribution, and reproduction in any medium, provided the original work is properly cited.

Cyclic voltammetric behaviors of three analgesics, acetaminophen (AAP), acetylsalicylic acid (ASA), and dipyrone (DP), were studied using nano-riboflavin-modified glassy carbon electrode. One well-defined oxidation peak each for AAP and ASA and three oxidation peaks for DP were observed. The influence of $\mathrm{pH}$, scan rate, and concentration reveals irreversible diffusion controlled reaction. The SEM analysis confirmed good accumulation of the drugs on the electrode surface. Calibration was made under the maximum peak current conditions. The concentration range studied for the determination of drugs was 0.02 to $0.4 \mu \mathrm{g} \mathrm{mL} \mathrm{m}^{-1}$ for AAP and ASA and 0.025 to $0.4 \mu \mathrm{g} \mathrm{mL} L^{-1}$ for DP. The lower limit of detection observed for AAP, ASA, and DP was $0.016,0.007 \mu \mathrm{g} \mathrm{mL}^{-1}$, and $0.013 \mu \mathrm{g} \mathrm{mL}^{-1}$, respectively. The suitability of the method for the determination of these analgesics in pharmaceutical preparations and urine samples was also ascertained.

\section{Introduction}

Stripping voltammetry is one of the most important and significant electroanalytical methods to determine the trace level pharmaceutical samples. By employing anodic/cathodic/adsorptive-stripping voltammetry, $\mu \mathrm{g} / \mathrm{mL}$ to $\mathrm{ng} / \mathrm{mL}$ range of drugs can be determined. Sensitivity of the method can be increased by carrying out the stripping using differential pulse or square wave mode.

In recent years, numerous investigations have been carried out on electrochemical biosensors to improve the rapidity, selectivity, and sensitivity and to reduce the cost of analysis [1]. The understanding of the versatile chemistry of flavins is of extreme importance and has been the focus of many investigations [2]. The flavins have in common the isoalloxazine ring system, where the redox process occurs. The redox process of the flavins is thermodynamically reversible, irrespective of whether one or two electrons per flavin molecule are being transferred [3]. Many electrochemical investigations have been made with the goal of elucidating the mechanism and using flavins as electrode modifier. Surface or bulk modified carbon paste electrodes with flavins are useful configurations to incorporate electroactive species for analytical purposes [4].

The riboflavin (RF), vitamin B2, is an essential precursor of flavin adenine dinucleotide and flavin mononucleotide coenzymes. The chemical environment around riboflavin modulates its redox behaviour by enhancing or preventing the targeted redox reaction. The best electrocatalytical activity was found to be the mixed system composed of riboflavin and 3,3'-thiodipropionic acid [5]. A stable, novel Nafionriboflavin functional membrane modified gold electrode was constructed and used for the study on the electron transfer of cytochrome C, superoxide dismutase, and hemoglobin [6]. A chemically modified electrode exhibiting electrocatalytic response towards dioxygen was constructed by adsorbing 
the mediator riboflavin onto spectroscopic graphite [7]. The adsorbed riboflavin as an effective mediator can accelerate the reduction of dioxygen, which accepts two electrons from the reduced riboflavin to generate hydrogen peroxide. The rate constants of the electrocatalytic reaction in various $\mathrm{pH}$ solutions were determined using a rotating disc electrode modified with riboflavin [8-10]. The electrochemical behavior of riboflavin (RF) adsorbed on different surfaces of inorganic matrices was investigated using modified carbon paste electrodes. The immobilization of RF on these materials indicated high electrode stability avoiding leaching out of the electroactive species (RF) from the electrode surface [11]. An original electroenzymatic system, reductase-riboflavin, was employed for the improvement of dehydrogenase-based biosensors in the amperometric detection of lactate [12]. However, the development of RF-modified electrode for the electroanalysis of drugs has not been given much attention. Hence it is thought of developing nano-riboflavin-modified electrode for the determination of certain common drugs.

Acetaminophen (AAP) is a popular analgesic and antipyretic agent [13]. Many assays have been determined using titrimetry, chromatography, fluorometry, colorimetry, spectrophotometry, electrochemical, and pulse perturbation techniques [14-18]. Electrochemical studies of AAP using various electrodes such as conducting polymer-modified electrode [19], sodium montmorillonite clay-modified electrode [20], nano-polypyrrole-modified glassy carbon electrode [21], pumice mixed carbon electrodes [22], $\mathrm{C}_{60^{-}}$ modified glassy carbon electrode [23], PANI-MWCNTs composite-modified electrode [24], single-wall carbon nanotube-dicetyl phosphate film [25], and nickel magnetic nanoparticles-modified electrodes [26] were reported.

Acetylsalicylic acid (ASA) possesses anti-inflammatory, analgesic and antipyretic properties. Partial least-squares algorithm, reversed-phase sequential injection chromatography technique, ultraviolet, fluorescence, infrared methods, chromatographic procedures (HPLC), and atomic absorption spectrometry have been described for the determination of ASA $[27,28]$. These methods are not frequently used because of tedious sample preparations involved, expensive apparatus and usually needed, extraction procedures. Ion selective electrodes have been developed showing high specificity, good detection limits, and relatively low cost [29]. The electrochemical oxidation of salicylic acid in pharmaceuticals formulations of ASA has been studied on a glassy carbon electrode using cyclic voltammetric and differential pulse voltammetric methods [30]. An electrochemical sensor for acetylsalicylic detection using both carbon paste electrode and graphite pencil electrode has been described [31].

Dipyrone (DP) is another analgesic, antipyretic, and anti-inflammatory drug. It has been restricted or banned in some countries because of the alleged risks of adverse reactions [32]. Flow injection amperometric and liquid chromatography/mass spectrometry methods have been described for the determination of DP [33-36]. Spectrophotometric methods such as ultraviolet-visible absorption, fluorescence, and chemiluminescence have also been frequently reported for DP determination [37].
The adverse effects of the common drugs either in small or larger doses necessitate the development of newer analytical techniques or modification of existing methods for improved sensitivity. Thus, it is planned to utilize nanoriboflavin-modified electrode for the electroanalysis of the three drugs. This paper reports the stripping voltammetric determination of the above said three common analgesics using nano-RF-modified glassy carbon electrode.

\section{Experimental}

2.1. Methods and Material. EG\&G M 273A Electrochemical Analyzer-Princenton Applied Research Corporation (Princenton, NJ, USA) was employed mainly for carrying out electroanalytical studies. Three analgesic drugs of acetaminophen, acetylsalicylic acid and dipyrone were purchased from SIGMA (St.Louis, Mo, USA) and used as such. Riboflavin was purchased from Merck (KGaA, Darmstadt, Germany). The structure and physical parameters are presented in Table 1. The stock solutions were made up in double distilled TKA-LAB (Niederelbert, Germany) purified water. For studies in aqueous media, Britton Robinson buffers, 4.0, 7.0, 9.2, and $0.1 \mathrm{moL} \cdot \mathrm{dm}^{-3} \mathrm{KOH}, \mathrm{KCl}$, and $\mathrm{H}_{2} \mathrm{SO}_{4}$ were used as the medium for the analysis.

2.2. Procedure. Analyte solution kept in electrochemical cell of $15 \mathrm{~mL}$ capacity was subjected to purging with high pure nitrogen for 15 minutes under stirring. After purging nitrogen, voltammograms were recorded under blanketing. Great care was taken in the electrode pretreatment to get reproducible results. The glassy carbon electrode was pretreated in two ways: mechanical polishing over a velvet microcloth with an alumina suspension and electrochemical treatment by applying a potential of $1.5 \mathrm{~V}$ for 2 seconds

\subsection{Preparation of Nanosize Riboflavin-Modified Glassy Car-} bon Electrode (RF/GCE). The typical cyclic voltammogram of $0.1 \mathrm{M}$ riboflavin in aqueous $0.1 \mathrm{M}$ solution of $\mathrm{KCl}$ medium at the scanning potential $50 \mathrm{mV} \mathrm{s}^{-1}$ is shown in Figure 1. One oxidation peak at $-380 \mathrm{mV}$ and one reduction peak at $-660 \mathrm{mV}$ were observed in the first cycle. As the number of cycles increased between the potential -800 and $400 \mathrm{mV}$, the peak current decreased which indicates the absence of further reaction and adsorption of the compound on the working electrode surface. Thickness of the film was controlled coulometrically, and $0.1 \mu$ thick films were used in all cases. The SEM photograph reveals the deposition of nanosize $(100 \mathrm{~nm})$ fiber-like structure of RF film on GCE. After each cycle, care was taken to remove the riboflavin film present on the glassy carbon electrode during cleaning of the electrode surface. This was done in a bath containing $1: 1 \mathrm{HCl} / \mathrm{H}_{2} \mathrm{O}$ and $1: 1 \quad \mathrm{H}_{2} \mathrm{O}_{2}$ /acetic acid mixture before usual surface treatment procedure which involves mechanical polishing and electrochemical treatments. Nitric acid (6M) solution was used to clean the cell. The electrode stability of RF filmmodified electrode is of prime importance in these studies. The electrode was found to be stable in the medium used for the study. It showed a decrease in peak current after 2 days of 
TABLE 1: Structure and physical parameters of drugs.

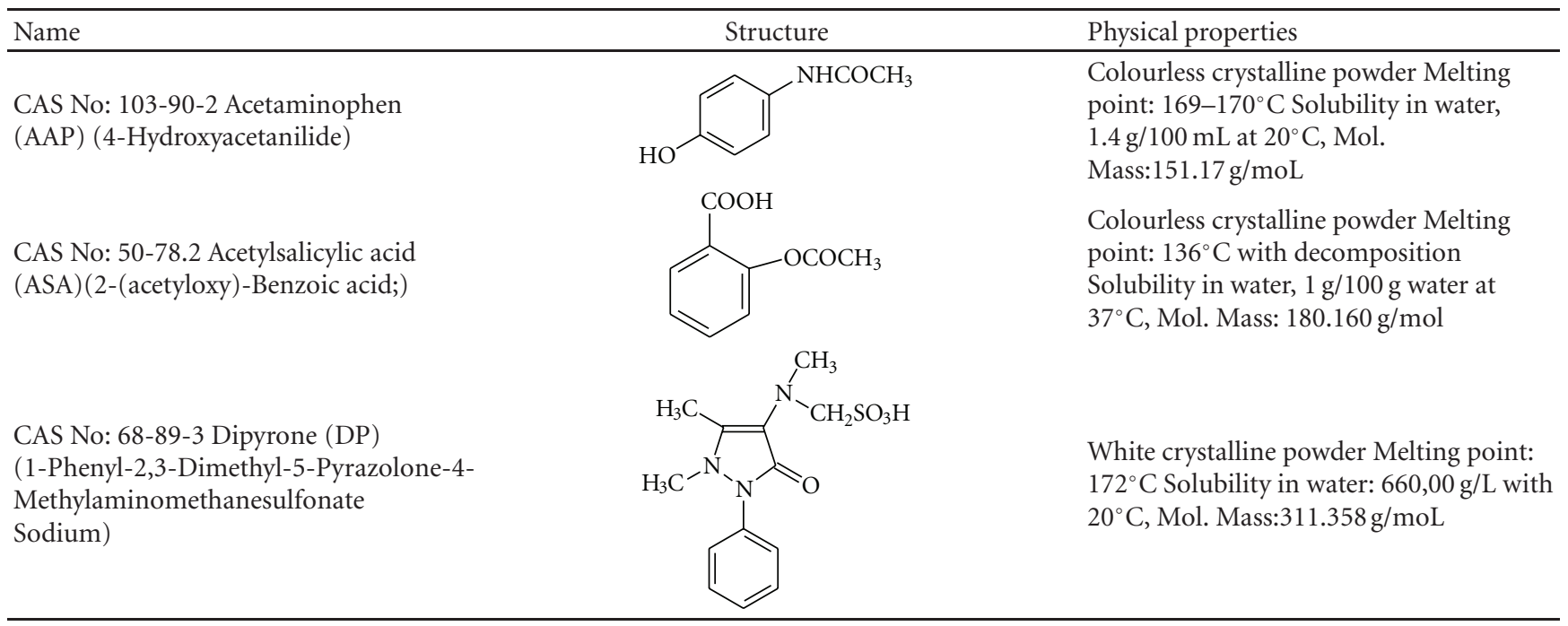

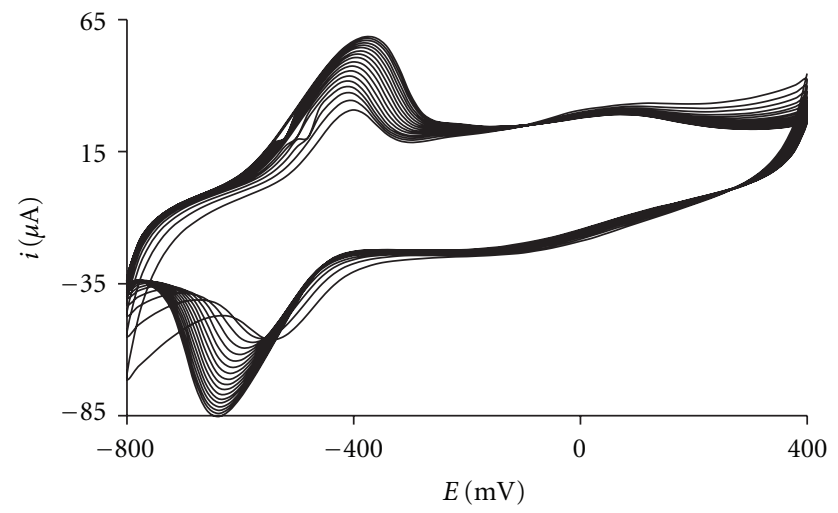

Figure 1: Cyclic voltammogram of $0.1 \mathrm{M}$ riboflavin at $\mathrm{pH} 7.0$ on GCE.

its preparation, and hence, the electrode is found to lose its efficiency after this period. The response time of the electrode was very fast and all measurements could be carried out easily and quickly.

\section{Results and Discussions}

3.1. Effect of $p H$. Cycil voltammograms (CV) of $250 \mu \mathrm{g} \mathrm{mL}^{-1}$ of AAP, ASA and DP were recorded at a sweep rate $100 \mathrm{mV} \mathrm{s}^{-1}$ in the five selected $\mathrm{pH}$ media $(1.0,4.0,7.0,9.2$, and 13.0.), and the results were compared to understand the influence of $\mathrm{pH}$ on the voltammetric behaviour of the three drugs. AAP and ASA exhibited single oxidation peak in the CV, whereas DP showed three anodic peaks and one cathodic peak. The peak potential with higher peak current was chosen for comparison. The peak potential (Figure 2) and current (Figure 3 ) were measured and correlated with $\mathrm{pH}$. As the $\mathrm{pH}$ increased, the peak potential decreased showing lesser energy requirement for the oxidation in basic medium. Sharpness of peak was very good in $\mathrm{pH} 1.0$. Peak

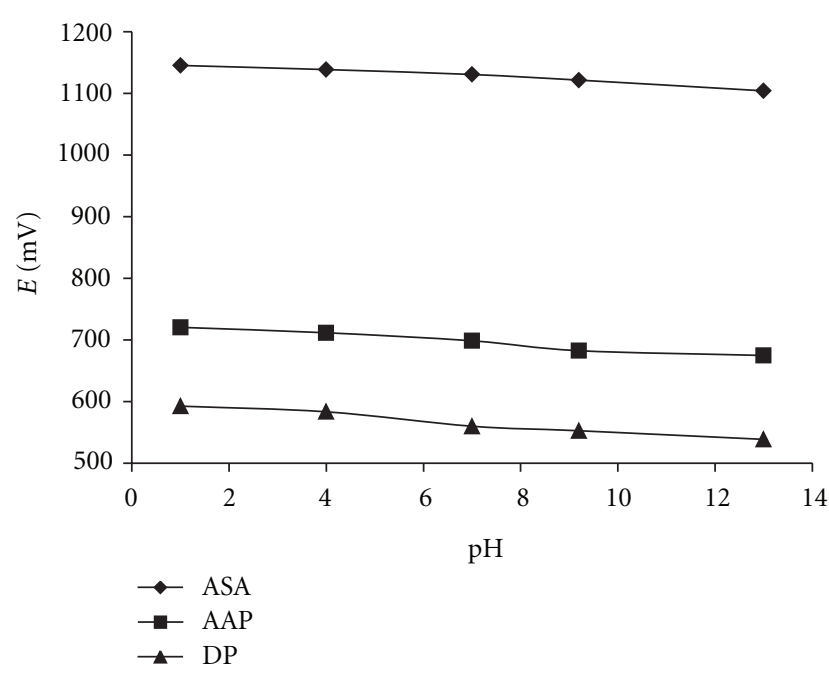

FIGURE 2: Plot of peak potential versus $\mathrm{pH}$.

current decreased in neutral condition, and a small increase was found in base medium (Figure 3). For all the three analgesics maximum peak current was noticed at $\mathrm{pH}$ 1.0. Hence analytical point of view, $\mathrm{pH} 1.0$ was chosen as the optimum $\mathrm{pH}$.

3.2. Voltammetric Studies of Drugs at pH 1.0. Cyclic voltammetric behaviour of ASA, AAP and DP was studied in the concentration $250 \mu \mathrm{g} \mathrm{mL}^{-1}$ in aqueous $\mathrm{pH} 1.0$ (Figure 4) at scan rate $100 \mathrm{mVs}^{-1}$. The compound ASA and AAP showed only one well-defined anodic peak and DP revealed three anodic and one cathodic peaks. At pH 1.0 AAP and ASA exhibited (Figures 5(a) and 6(a)) one oxidation peak, and DP exhibited (Figure 7(a)) three anodic and one cathodic peaks. The same number of peaks was observed at various sweep rates. Correlation of peak current with sweep rate resulted in a curve line, whereas the plot of ip versus $v^{1 / 2}$ 


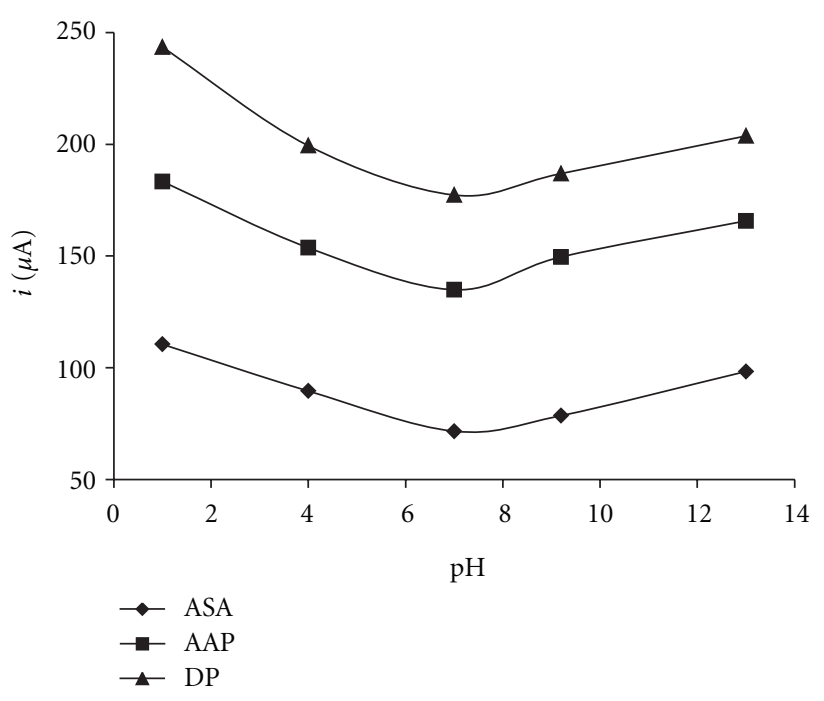

Figure 3: Plot of peak current versus $\mathrm{pH}$.

resulted in straight lines. The plot of log ip versus log $v$ correlation equation also led to a straight line (with a slope value of 0.3013 for AAP 0.2987 for ASA 0.2815 for DP). All the above facts confirming the diffusion controlled nature of the reaction. As the concentration increased, the peak current also increased and resulted in a straight line. The correlation of peak potential with $\log v$ shows linearity. The transfer coefficient, " $\alpha n$ " value $(0.4999$ for AAP, 0.7486 for ASA and 0.6586 for DP) was calculated from the slope of the straight line. The fractional value of " $\alpha n$ " and absence of peak in the reverse scan suggest irreversible electron transfer. The voltammetric behaviour of analgesic on RF/GCE showed higher current responsibility than that on GCE.

The number of electrons transferred was calculated from controlled potential coulometric studies. At $\mathrm{pH} 1.0$, the charge consumed for oxidation was found out, and the number of electrons transferred was calculated as two for AAP, ASA, and DP. The standard rate constant ks was calculated from the intercept of $\log$ ip versus $E--E_{i}$ plot. The value of $k_{s}$ is $5.112 \times 10^{-5} \mathrm{~cm} \mathrm{~s}^{-1}$ for AAP, $9.428 \times$ $10^{-5} \mathrm{~cm} \mathrm{~s}^{-1}$ for ASA, and $7.872 \times 10^{-5} \mathrm{~cm} \mathrm{~s}^{-1}$ for DP. The lower value of the rate constant ks confirms irreversible electron transfer. The standard rate constant was calculated from the following equation:

$$
i_{p}=n F A C k_{s} \exp \left[-\frac{\alpha n}{R T}-\left(E_{i}-E_{o}\right)\right]
$$

where, $i_{p}=$ peak current, $n=$ number of electrons transferred, $F=$ Faraday constant, $96487 \mathrm{C} \mathrm{mol}^{-1}, A=$ area of the electrode, $\mathrm{cm}^{2}, C=$ concentration of the electrolyte, moles $\mathrm{cm}^{-3}$, $k_{s}=$ standard rate constant, $\mathrm{cm} \mathrm{s}^{-1}, \alpha n=$ transfer coefficient, $R=$ gas constant, $8.314 \mathrm{~J} \mathrm{~K}^{-1} \mathrm{~mol}^{-1}, T=$ temperature, $K$, $E_{o}=$ peak potential, and $V, E_{i}=$ potential at the foot of the response.
3.3. Square Wave Stripping Voltammetric (SWSV) Analysis of Drugs. Cyclic voltammetric results revealed good electroactivity of the drugs on the RF-modified electrode at $\mathrm{pH}$ 1.0. Squarewave mode was employed for stripping voltammetric studies and was found to perform well in the determination of all the three analgesic drugs. The accumulation potential was varied between 500 and $750 \mathrm{mV}$ for AAP, 750 and $950 \mathrm{mV}$ for ASA, and 300 and $600 \mathrm{mV}$ for DP. Higher peak response was obtained only at 600,850 , and $550 \mathrm{mV}$, respectively, for AAP, ASA, and DP. The deposition time was varied between 5 and $60 \mathrm{sec}$ for all drugs and maximum peak current was observed at a deposition time of $10 \mathrm{~s}$ for ASA and DP and $30 \mathrm{~s}$ for AAP. The accumulation of the three analgesics on the modified electrode surface under the optimum accumulation conditions was understood from the changes in the electrode surface before and after accumulation process. SEM was employed to study the surface morphology of the three accumulated analgesics on the electrode. Figure 8(a) reveals fiber knitting-like structure of GCE and Figure 8(b) shows dense mixed needle like structure of RF-modified electrode surface. The drug AAP showed sponge like structure (Figure 8(c)). ASA adsorbed exhibited knitted fiber-like morphology (Figure 8(d)), and DP exhibited uniformly mixed fiber and sponge like morphology (Figure 8(e)).

The initial scan potential was varied from 0 to $400 \mathrm{mV}$ for AAP, 200 to $700 \mathrm{mV}$ for ASA, and -300 to $300 \mathrm{mV}$ for DP, and optimum value was obtained at $200 \mathrm{mV}$ for AAP and ASA and $-300 \mathrm{mV}$ for DP. The stripping peak current increased initially up to $50 \mathrm{mV}$ for ASA and DP and decreased. Hence, this value, $50 \mathrm{mV}$ was considered as optimum. For AAP, increase in square wave amplitude, resulted in a decrease in peak current, and hence, $25 \mathrm{mV}$ was taken as the optimum amplitude.

The dependence of the peak intensity on the frequency was studied between 20 and $100 \mathrm{~Hz}$ at a constant value of the step potential of $2 \mathrm{mV}$. Maximum peak current was observed at $40 \mathrm{~Hz}$. As the frequency increased above $40 \mathrm{~Hz}$, the peak current decreased and the peak was broadened. When the step potential increased to higher value upto $10 \mathrm{mV}$, a decrease in peak current was noticed. Hence, a frequency of $40 \mathrm{~Hz}$ and a step potential of $2 \mathrm{mV}$ were used. The square wave stripping voltammograms obtained under optimum experimental conditions (Table 2) for three analgesics drugs at concentration of $0.1 \mu \mathrm{g} \mathrm{mL}^{-1}$ are given in Figures 5(b), 6(b), and 7(b).

3.4. Analytical Characteristics. The experimental results showed that the peak current increased with the increase in concentration of drugs. A calibration plot was made, and linear dependence of peak current with concentration was observed (Figure 9). The reproducibility of the stripping signal was realized in terms of relative standard deviation for 7 identical measurements carried out at a concentration level of $0.25 \mu \mathrm{g} \mathrm{mL}^{-1}$ (Table 3). The lower limit of detection was found to be $0.016 \mu \mathrm{g} \mathrm{mL}^{-1}, 0.007 \mu \mathrm{g} \mathrm{mL}^{-1}$ and $0.013 \mu \mathrm{g} \mathrm{mL}^{-1}$ for AAP, ASA, and DP, respectively. 


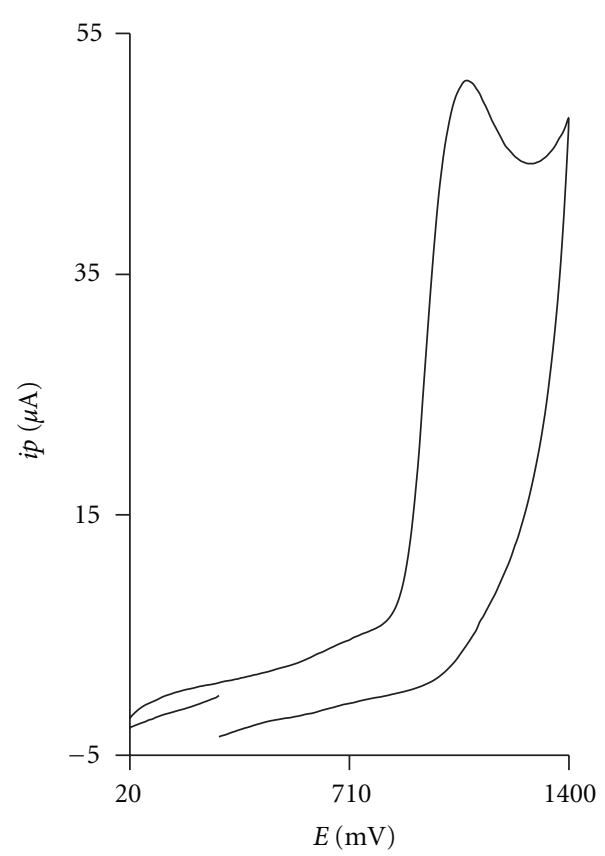

(a)

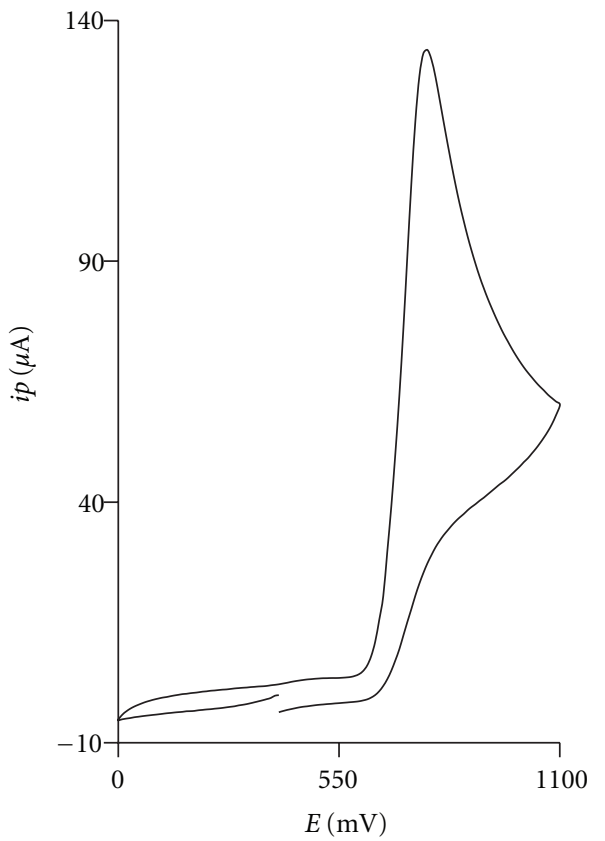

(b)

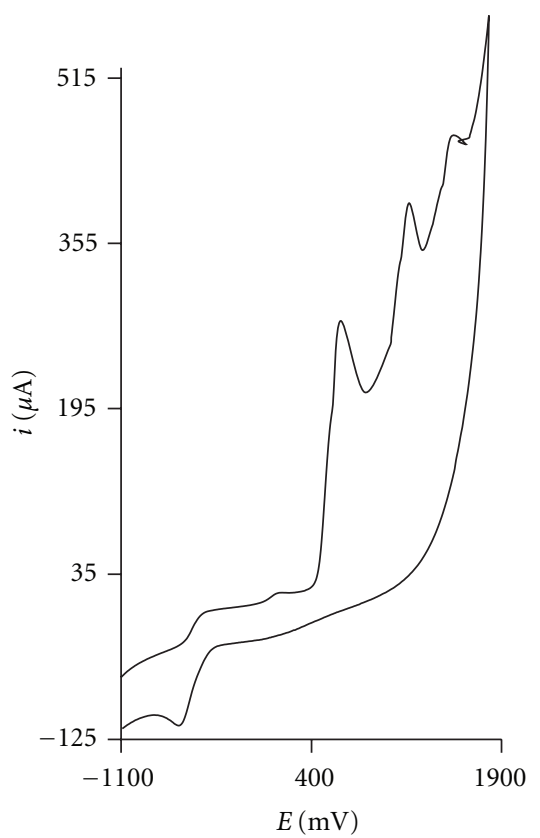

(c)

Figure 4: Cyclic voltammogram of (a) ASA, (b) AAP, and (c) DP at pH 1.0 on GCE.

SWSV method involving riboflavin modified glassy carbon electrode is considered to be the best method for the determination of the analgesics compared to other available methods (Table 4).

Determination of AAP generally suffered from the interference of $p$-aminophenol as well as ascorbic acid, caffeine, glucose, and urea [23]. Hence, a systematic study of interference due to these compounds was carried out for all the three analgesics. Specificity of the nano-RF-modified electrode to $0.124 \mu \mathrm{g} \mathrm{mL}^{-1}$ of AAP, ASA, and $0.186 \mu \mathrm{g} \mathrm{mL}^{-1}$ of DP in the presence of ascorbic acid, caffeine, glucose, $p$-aminophenol, and urea was checked by recording square wave stripping voltammograms for oxidation of AAP, ASA, and DP after addition of varying concentration of each interferent $\left(0.01-0.1 \mu \mathrm{g} \mathrm{mL}^{-1}\right)$. Ascorbic acid, glucose, caffeine, and urea do not affect the peak current of drugs even up to 10-fold-excess of interferent. However, in the case of AAP, oxidation peak due to $p$-aminophenol started merging 


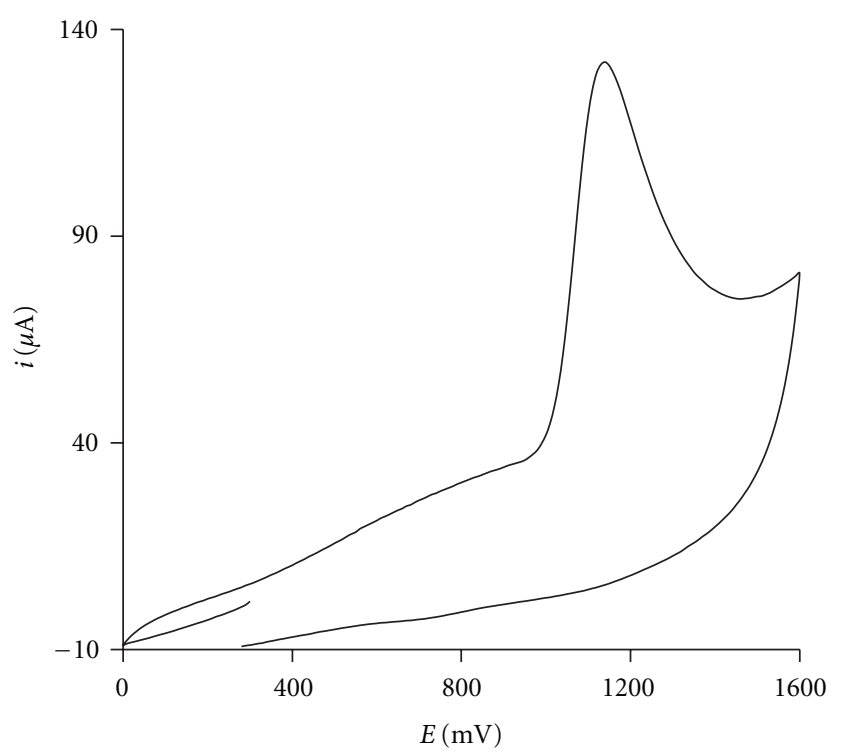

(a)

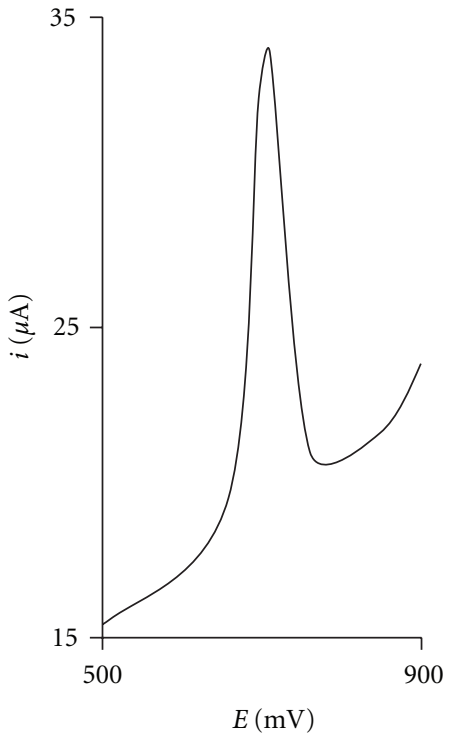

(b)

FIGURe 5: (a) Cyclic voltammogram of ASA at $\mathrm{pH} 1.0$ on RF/GCE; scan rate $100 \mathrm{mV} \mathrm{s}^{-1}$ (b) SWSV of ASA on RF/GCE under optimum conditions.

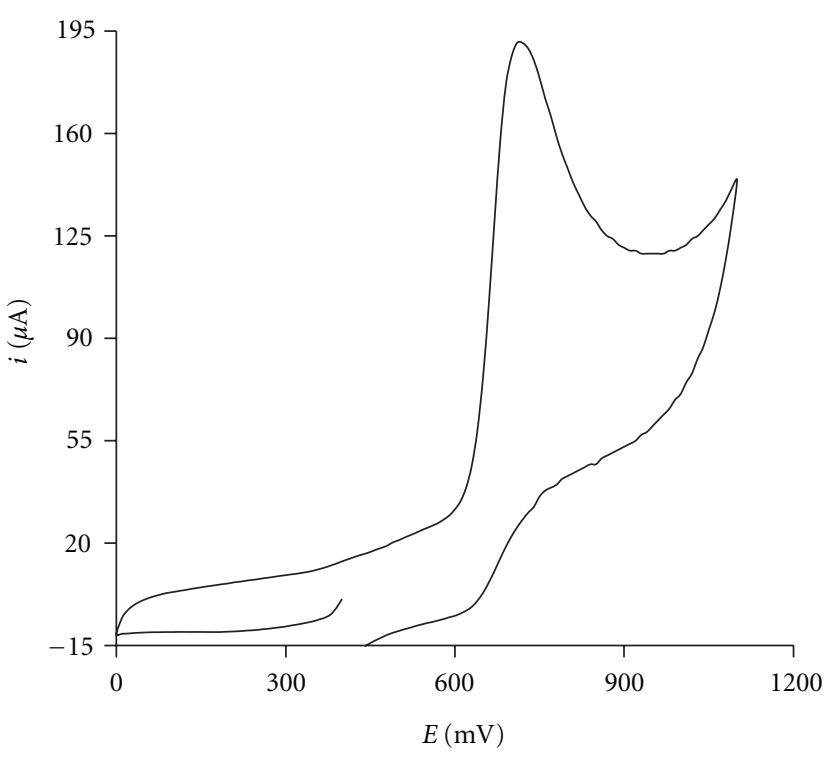

(a)

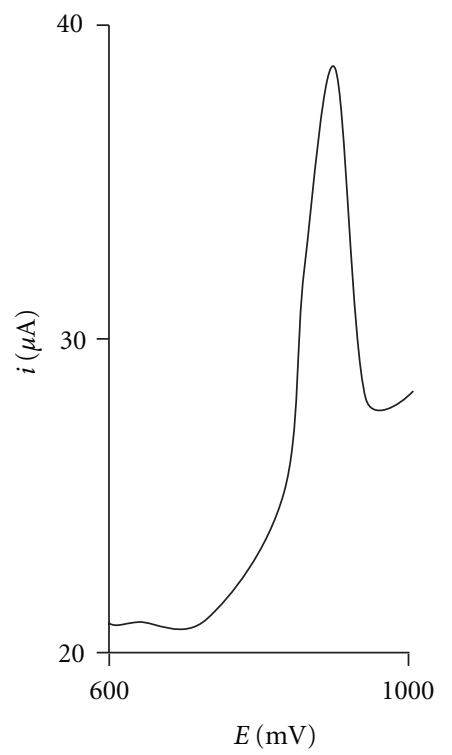

(b)

FIGURE 6: (a) Cyclic voltammogram of AAP at $\mathrm{pH} 1.0$ on RF/GCE; scan rate $100 \mathrm{mV} \mathrm{s}^{-1}$ (b) SWSV of AAP on RF/GCE under optimum conditions.

with that of AAP from $0.07 \mu \mathrm{gLL}^{-1}$ concentration of the interferent.

\subsection{Proposed Method for the Determination of Drugs in Phar-} maceutical and Urine Samples. The pharmaceutical samples analyzed were collected from medical shops at Karaikudi, Tamilnadu, India. Various tablets and injection having acteaminophen, acetylsalicylic acid, and dipyrone were examined for estimation of content of drugs. Stripping voltammograms of the drugs at $\mathrm{pH} 1.0$ were recorded under optimised conditions. The concentration of the analgesics in commercial formulations determined by the proposed method was in good agreement with the reported value of the company (Table 5).

For the measurement of drugs in urine, samples collected after $8 \mathrm{~h}$ from the administration of the drug were 


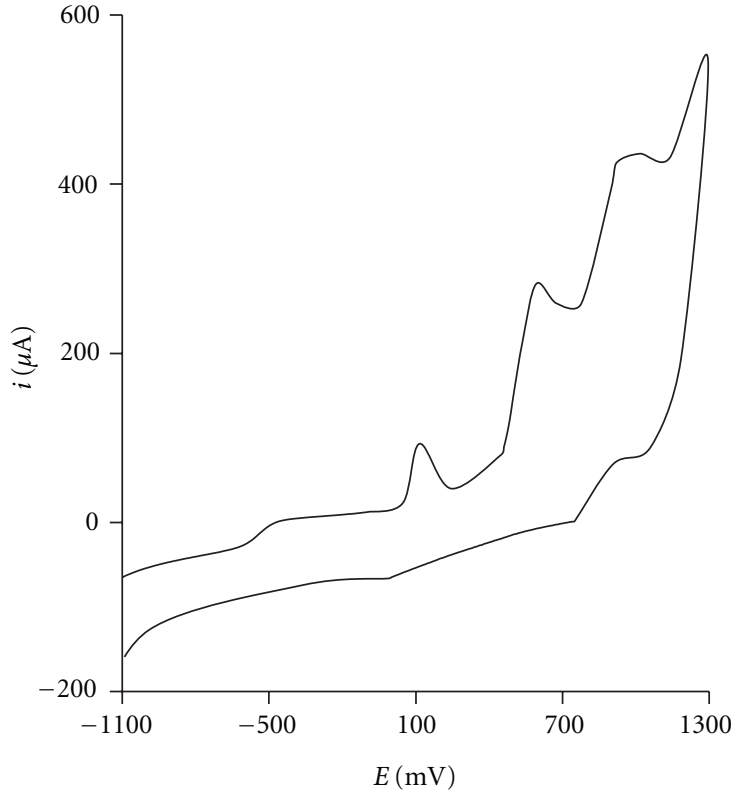

(a)

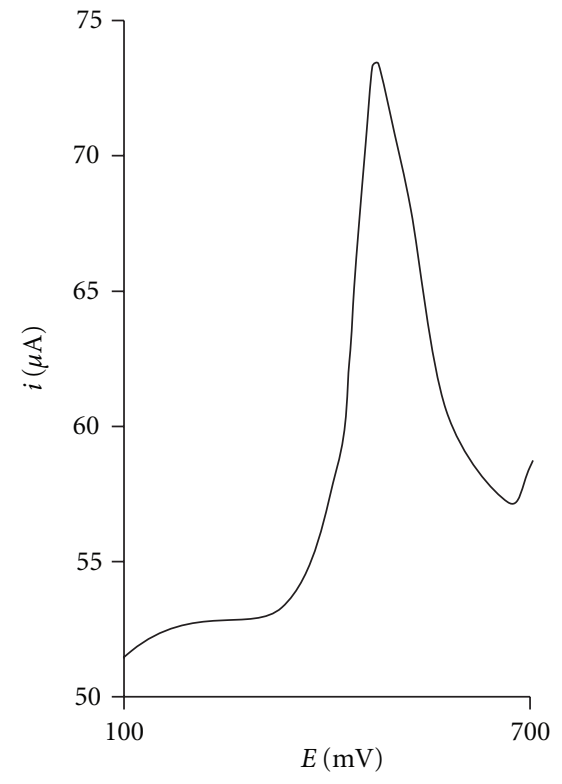

(b)

Figure 7: (a) Cyclic voltammogram of DP at $\mathrm{pH} 1.0$ on RF/GCE; scan rate $100 \mathrm{mV} \mathrm{s}^{-1}$ (b) SWSV of DP on RF/GCE under optimum conditions.

TABLE 2: Optimum experimental conditions in SWSV.

\begin{tabular}{|c|c|c|c|c|c|c|}
\hline \multirow{2}{*}{ Parameters } & \multicolumn{3}{|c|}{ Range studied } & \multicolumn{3}{|c|}{ Optimum value } \\
\hline & ASA & AAP & DP & ASA & AAP & DP \\
\hline $\mathrm{pH}$ & 1.0 to 13.0 & 1.0 to 13.0 & 1.0 to 13.0 & 1.0 & 1.0 & 1.0 \\
\hline Accumulation potential $(\mathrm{mV})$ & 750 to 950 & 500 to 750 & 300 to 600 & 850 & 600 & 550 \\
\hline Accumulation time (Sec) & 5 to 60 & 5 to 60 & 5 to 60 & 10 & 30 & 10 \\
\hline Initial scan potential (mV) & 200 to 700 & 0 to 400 & -300 to 300 & 200 & 200 & -300 \\
\hline Square wave amplitude (mV) & 25 to 150 & 25 to 150 & 25 to 150 & 50 & 25 & 50 \\
\hline Frequency $(\mathrm{Hz})$ & 20 to 100 & 20 to 100 & 20 to 100 & 40 & 40 & 40 \\
\hline Scan increment $(\mathrm{mV})$ & 2 to 20 & 2 to 20 & 2 to 20 & 4 & 4 & 4 \\
\hline Scan rate $(\mathrm{mV} / \mathrm{sec})$ & 10 to 80 & 10 to 60 & 20 to 80 & 60 & 40 & 50 \\
\hline Stirring rate (rpm) & 50 to 250 & 50 to 250 & 50 to 250 & 250 & 250 & 250 \\
\hline Rest period (Sec) & 2 to 10 & 2 to 10 & 2 to 10 & 5 & 5 & 5 \\
\hline
\end{tabular}

TABLE 3: SWSV behaviour of analgesic drugs.

\begin{tabular}{lccc}
\hline Drugs & Range studied $(\mu \mathrm{g} / \mathrm{mL})$ & LOD $(\mu \mathrm{g} / \mathrm{mL})$ & of RSD \\
\hline Acetaminophen & 0.020 to 0.4 & 0.016 & 2.3 \\
Acetylsalicylic acid & 0.020 to 0.4 & 0.007 & 2.8 \\
Dipyrone & 0.025 to 0.4 & 0.013 & 2.3 \\
\hline
\end{tabular}

TABLE 4: Comparison of available methods.

\begin{tabular}{lcc}
\hline Methods & & \multicolumn{2}{c}{ LOD in $\mu \mathrm{g} \mathrm{mL}^{-1}$} \\
& AAP & ASA \\
\hline Voltammetric determination $[28,29,37]$ & $0.09-0.93,38.0$ & $1.0-60.0$ \\
Flow injection-FT-IR spectrometric [38] & 8.0 & $22.4,1.8$ \\
HPLC method $[39,40]$ & 31.6 & 25.02 \\
Spectrophotometric determination $[17,41]$ & $4.0,0.5-20.0$ & $1.0-40.0$ \\
Flow injection amperometric determination $[35,42,43]$ & 20.54 & 64.45 \\
\end{tabular}




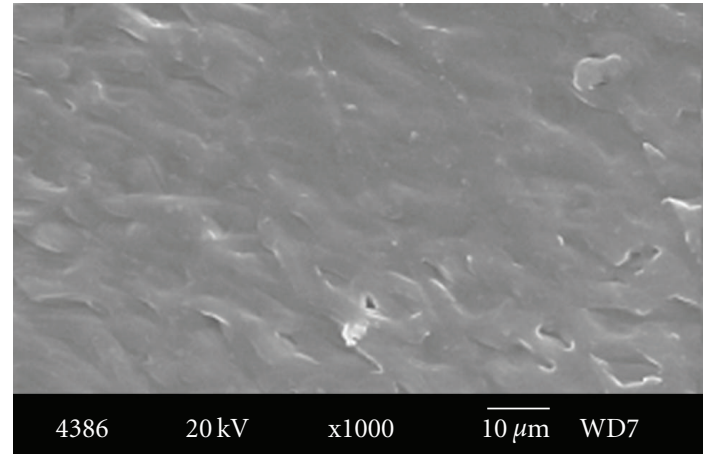

(a)

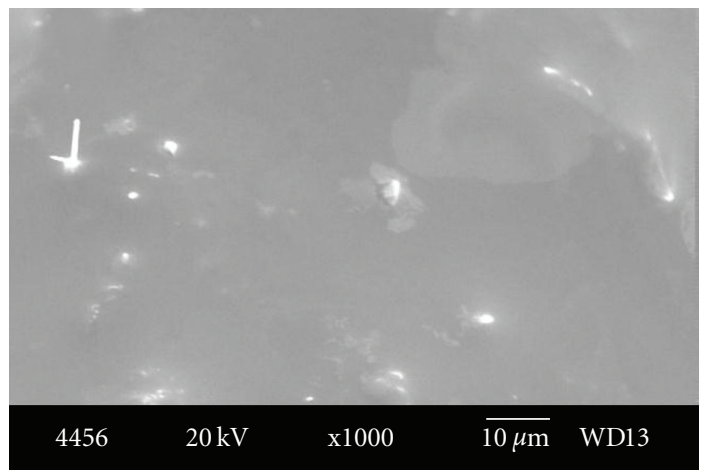

(c)

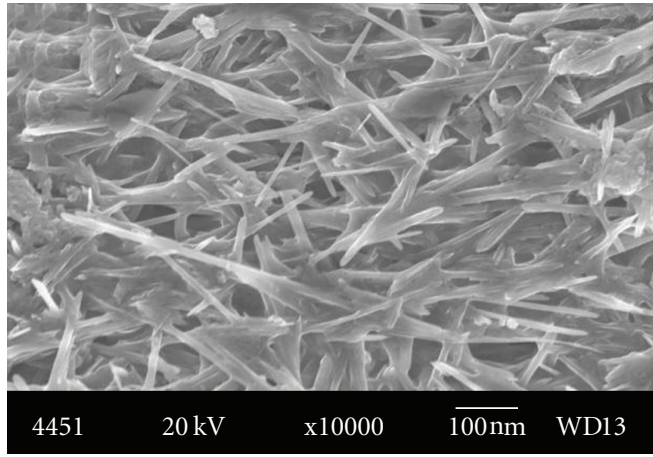

(b)

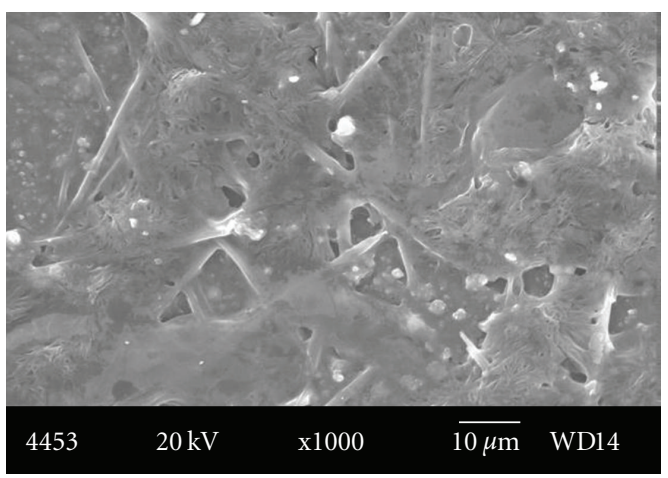

(d)

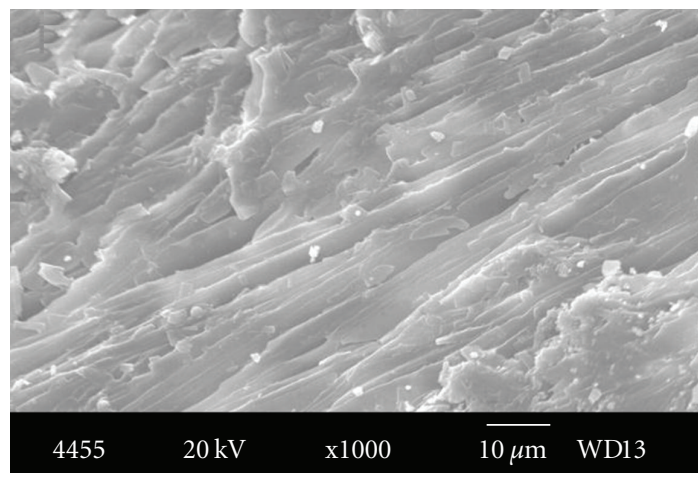

(e)

Figure 8: SEM photographs of (a) GCE surface, (b) Nano RF/GCE, (c) AAP accumulated RF/GCE, (d) ASA accumulated RF/GCE, (e) DP accumulated RF/GCE.

used. $1.0 \mathrm{~mL}$ of the urine sample was mixed with $0.1 \mathrm{M}$ $\mathrm{H}_{2} \mathrm{SO}_{4}$ solution, and the $\mathrm{pH}$ was adjusted to 1.0 . The SWSV was carried out under the optimised experimental conditions. This experiment was repeated for 5 times, and the average weight of drugs in $1.0 \mathrm{~mL}$ of urine sample was $0.12 \mu \mathrm{g}$ for AAP, $0.23 \mu \mathrm{g}$ for ASA, and $0.27 \mu \mathrm{g}$ for DP. There was no appreciable interference due to the presence of other compounds present in the urine. There was no degradation of the drug in solution during the experiments. The method described is simple and suitable for the determination of drugs. Repetition rate was high. Hence, the proposed method can be used as a better alternative to spectrophotometric or chromatographic methods.

\section{Conclusion}

Electrooxidation of three analgesics AAP, ASA, and DP showed irreversible two electron transfer oxidation on nanoRF-modified glassy carbon electrode in the $\mathrm{pH}$ range 1.0 to 13.0. The oxidation of drugs was controlled by diffusion. The study on the influence of $\mathrm{pH}$ revealed $\mathrm{pH} 1.0$ as the best $\mathrm{pH}$ for the development of analytical procedure. Detailed square wave stripping voltammetric studies were carried out at $\mathrm{pH}$ 1.0, and optimum accumulation and stripping conditions were arrived at. The concentration was varied under optimum experimental conditions, and calibration was made. From the SEM photographs, accumulation of drugs was understood. Lower limit of detection for all 
TABLe 5: Amount of drugs in tablets determined by SWSV in tablets.

\begin{tabular}{|c|c|c|c|c|}
\hline Brand name & Company name & Tablets (mg) & Experimental value (mg) & $\%$ of RSD \\
\hline \multicolumn{5}{|l|}{ Acteaminophen } \\
\hline Calpol & Glaxosmithkline & 500 & 492 & 2.5 \\
\hline Crocin & Glaxosmithkline & 500 & 495 & 3.1 \\
\hline Colimex tabs & Wallace & 500 & 494 & 2.3 \\
\hline Doliprane & Nicholas piramal & 500 & 498 & 2.7 \\
\hline Cyclopam & Indoco & 500 & 498 & 2.2 \\
\hline \multicolumn{5}{|c|}{ Acetyl salicylic acid } \\
\hline Disprin & Reckitts & 350 & 347 & 3.1 \\
\hline Mycropyrin & Nicholas piramal & 350 & 346 & 2.8 \\
\hline Asa50 & German remedies & 50 & 45 & 2.2 \\
\hline Colsprin 100 & Reckitts & 100 & 97 & 3.3 \\
\hline Ecosprin & Sidmak & 150 & 148 & 2.5 \\
\hline \multicolumn{5}{|l|}{ Dipyrone } \\
\hline Novalgin & Aventis & 500 & 498 & 2.5 \\
\hline
\end{tabular}

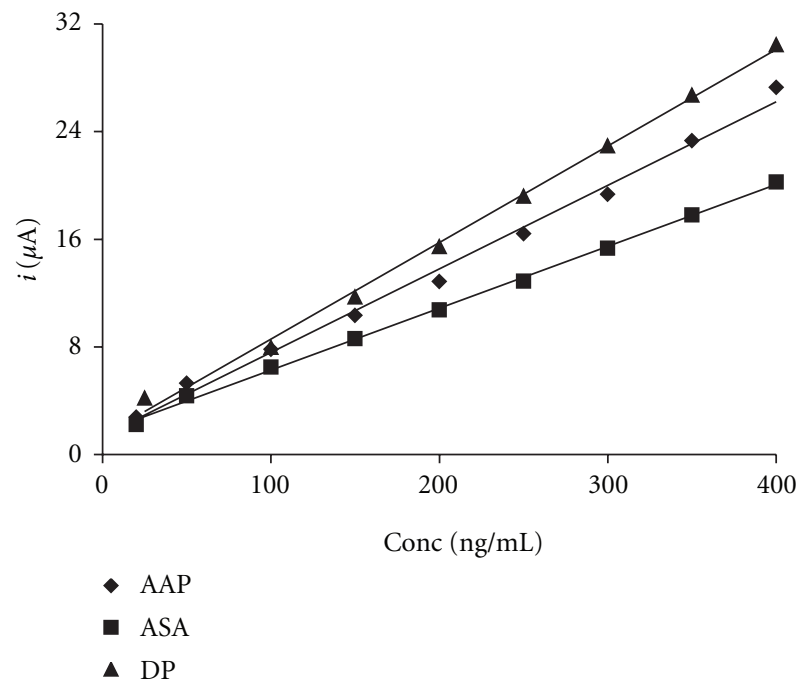

FIGURE 9: Calibration plot of peak current versus concentration.

the three analgesics are reported. This method can very well be used for the determination of three drugs in real samples also. This technique is simple and easy to carry out. LOD values from this study for all the three analgesics are compared with the reported values. On comparison, the proposed method is found to be best method for the determination of AAP, ASA, and DP.

\section{References}

[1] S. Rezaei-Zarchi, A. A. Saboury, A. Javed, A. Barzegar, S. Ahmadian, and A. Bayandori-Moghaddam, "Nano-composition of riboflavin-nafion functional film and its application in biosensing," Journal of Biosciences, vol. 33, no. 2, pp. 279-287, 2008.

[2] H. L. Schmidt and W. Schuhmann, "Reagentless oxidoreductase sensors," Biosensors and Bioelectronics, vol. 11, no. 1-2, pp. 127-135, 1996.
[3] A. Malinauskas, T. Ruzgas, and L. Gorton, "Tuning the redox potential of riboflavin by zirconium phosphate in carbon paste electrodes," Bioelectrochemistry and Bioenergetics, vol. 49, no. 1, pp. 21-27, 1999.

[4] M. Yamashita, S. S. Rosatto, and L. T. Kubota, "Electrochemical comparative study of riboflavin, FMN and FAD immobilized on the silica gel modified with zirconium oxide," Journal of the Brazilian Chemical Society, vol. 13, no. 5, pp. 635-641, 2002.

[5] R. F. Carvalhal, R. K. Mendes, and L. T. Kubota, "SAM effects on riboflavin: a biomimetic catalyst for glucose oxidation," International Journal of Electrochemcal Science, vol. 2, pp. 973985, 2007.

[6] S. Rezaei-Zarchi, A. A. Saboury, J. Hong et al., "Electrochemical behavior of redox proteins immobilized on Nafionriboflavin modified gold electrode," Bulletin of the Korean Chemical Society, vol. 28, no. 12, pp. 2266-2270, 2007.

[7] W. Sun, J. Kong, and J. Deng, "Electrocatalytic activity of riboflavin chemically modified electrode toward dioxygen reduction," Analytical Letters, vol. 29, no. 14, pp. 2425-2439, 1996.

[8] J. Zhang, Q. Chi, S. Dong, and E. Wang, "Orientation and electrocatalysis of riboflavin adsorbed on carbon substrate surfaces," Journal of the Chemical Society, Faraday Transactions, vol. 92, no. 11, pp. 1913-1920, 1996.

[9] P. Manisankar and A. Gomathi, "Mediated oxygen reduction at a glassy carbon electrode modified with riboflavin and 9,10anthraquinones," Journal of Power Sources, vol. 150, no. 1-2, pp. 240-246, 2005.

[10] P. Manisankar, A. M. Pushpalatha, S. Vasanthkumar, A. Gomathi, and S. Viswanathan, "Riboflavin as an electron mediator catalyzing the electrochemical reduction of dioxygen with 1,4-naphthoquinones," Journal of Electroanalytical Chemistry, vol. 571, no. 1, pp. 43-50, 2004.

[11] A. C. Pereira, A. D. S. Santos, and L. T. Kubota, "Electrochemical behavior of riboflavin immobilized on different matrices," Journal of Colloid and Interface Science, vol. 265, no. 2, pp. 351358, 2003.

[12] S. Cosnier, M. Fontecave, C. Innocent, and V. Niviere, "An original electroenzymatic system: Flavin reductase-riboflavin for the improvement of dehydrogenase-based biosensors. 
Application to the amperometric detection of lactate," Electroanalysis, vol. 9, no. 9, pp. 685-688, 2005.

[13] J. E. F. Reynolds, Ed., Martindale: The Extra Pharmacopoeia, The Pharmaceutical Press, London, UK, 29th edition, 1989.

[14] F. A. El-Yazbi, H. H. Hammud, and S. A. Assi, "Derivativeratio spectrophotometric method for the determination of ternary mixture of aspirin, paracetamol and salicylic acid," Spectrochimica Acta Part A, vol. 68, no. 2, pp. 275-278, 2007.

[15] K. Tungkananuruk, N. Tungkananuruk, and D. T. Burns, "Cyclic voltammetric determination of acetaminophen in paracetamol tablets," KMITL Science and Technology Journal, vol. 5, pp. 547-551, 2005.

[16] A. F. Lavorante, C. K. Pires, and B. F. Reis, "Multicommuted flow system employing pinch solenoid valves and micropumps. Spectrophotometric determination of paracetamol in pharmaceutical formulations," Journal of Pharmaceutical and Biomedical Analysis, vol. 42, no. 4, pp. 423-429, 2006.

[17] A. R. Zarei, A. Afkhami, and N. Sarlak, "Simultaneous spectrophotometric determination of paracetamol and salicylamide in human serum and pharmaceutical formulations by a differential kinetic method," Journal of AOAC International, vol. 88, no. 6, pp. 1695-1701, 2005.

[18] N. Pejić, L. Kolar-Anić, S. Anić, and D. Stanisavljev, "Determination of paracetamol in pure and pharmaceutical dosage forms by pulse perturbation technique," Journal of Pharmaceutical and Biomedical Analysis, vol. 41, no. 2, pp. 610-615, 2006.

[19] M. L. S. Silva, M. B. Q. Garcia, J. L. F. C. Lima, and E. Barrado, "Flow system with electrochemical detection for determination of paracetamol in pharmaceutical formulations," Portugaliae Electrochimica Acta, vol. 24, pp. 261-271, 2006.

[20] B. Muralidharan, G. Gopu, C. Vedhi, and P. Manisankar, "Determination of analgesics in pharmaceutical formulations and urine samples using nano polypyrrole modified glassy carbon electrode," Journal of Applied Electrochemistry, vol. 39, no. 8, pp. 1177-1184, 2009.

[21] B. Muralidharan, G. Gopu, C. Vedhi, and P. Manisankar, "Voltammetric determination of analgesics using a montmorillonite modified electrode," Applied Clay Science, vol. 42, no. 1-2, pp. 206-213, 2008.

[22] R. N. Goyal and S. P. Singh, "Voltammetric determination of paracetamol at C-modified glassy carbon electrode," Electrochimica Acta, vol. 51, no. 15, pp. 3008-3012, 2006.

[23] M. Li and L. Jing, "Electrochemical behavior of acetaminophen and its detection on the PANI-MWCNTs composite modified electrode," Electrochimica Acta, vol. 52, no. 9, pp. 3250-3257, 2007.

[24] D. Sun and H. Zhang, "Electrochemical determination of acetaminophen using a glassy carbon electrode coated with a single-wall carbon nanotube-dicetyl phosphate film," Microchimica Acta, vol. 158, no. 1-2, pp. 131-136, 2007.

[25] S. F. Wang, F. Xie, and R. F. Hu, "Carbon-coated nickel magnetic nanoparticles modified electrodes as a sensor for determination of acetaminophen," Sensors and Actuators B, vol. 123, no. 1, pp. 495-500, 2007.

[26] A. B. Moreira, I. L. T. Dias, G. O. Neto, E. A. G. Zagatto, M. M. C. Ferreira, and L. T. Kubota, "Solid-phase spectrofluorimetric determination of acetylsalicylic acid and caffeine in pharmaceutical preparations using partial least-squares multivariate calibration," Talanta, vol. 67, no. 1, pp. 65-69, 2005.

[27] D. Šatínský, I. Neto, P. Solich et al., "Sequential injection chromatographic determination of paracetamol, caffeine, and acetylsalicylic acid in pharmaceutical tablets," Journal of Separation Science, vol. 27, no. 7-8, pp. 529-536, 2004.

[28] R. Pirola, S. R. Bareggi, and G. De Benedittis, "Determination of acetylsalicylic acid and salicylic acid in skin and plasma by high-performance liquid chromatography," Journal of Chromatography B, vol. 705, no. 2, pp. 309-315, 1998.

[29] F. A. A. Matias, M. M. D. C. Vila, and M. Tubino, "Quantitative reflectance spot test for the determination of acetylsalicylic acid in pharmaceutical preparations," Journal of the Brazilian Chemical Society, vol. 15, no. 2, pp. 327-330, 2004.

[30] A. A. J. Torriero, J. M. Luco, L. Sereno, and J. Raba, "Voltammetric determination of salicylic acid in pharmaceuticals formulations of acetylsalicylic acid," Talanta, vol. 62, no. 2, pp. 247-254, 2004.

[31] V. Supalkova, J. Petrek, L. Havel et al., "Electrochemical sensors for detection of acetylsalicylic acid," Sensors, vol. 6, no. 11, pp. 1483-1497, 2006.

[32] E. Zylber-Katz, Y. Caraco, L. Granit, and M. Levy, "Dipyrone metabolism in liver disease," Clinical Pharmacology and Therapeutics, vol. 58, no. 2, pp. 198-209, 1995.

[33] R. C. Matos, L. Angnes, M. C. U. Araujo, and T. C. B. Saldanha, "Modified microelectrodes and multivariate calibration for flow injection amperometric simultaneous determination of ascorbic acid, dopamine, epinephrine and dipyrone," Analyst, vol. 125, no. 11, pp. 2011-2015, 2000.

[34] L. H. Marcolino-Júnior, M. F. Bergamini, M. F. S. Teixeira, E. T. G. Cavalheiro, and O. Fatibello-Filho, "Flow injection amperometric determination of dipyrone in pharmaceutical formulations using a carbon paste electrode," Farmaco, vol. 58, no. 10, pp. 999-1004, 2003.

[35] L. Penney, C. Bergeron, and A. Wijewickreme, "Simultaneous determination of residues of dipyrone and its major metabolites in milk, bovine muscle, and porcine muscle by liquid chromatography/mass spectrometry," Journal of AOAC International, vol. 88, no. 2, pp. 496-504, 2005.

[36] J. S. Albuquerque, V. L. Silva, F. Lima, A. N. Araujo, and M. C. B. S. M. Montenegro, "Determination of dipyrone in pharmaceutical products by flow injection analysis with potentiometric detection," Analytical Sciences, vol. 19, no. 5, pp. 691-694, 2003.

[37] M. F. S. Teixeira, L. H. Marcolino-Junior, O. Fatibello-Filho, E. R. Dockal, and E. T. G. Cavalheiro, "Voltammetric determination of dipyrone using a $N, N^{\prime}$-ethylenebis (salicylideneaminato)oxovanadium(IV) modified carbon-paste electrode," Journal of the Brazilian Chemical Society, vol. 15, no. 6, pp. 803-808, 2004.

[38] Z. Bouhsain, S. Garrigues, and M. De La Guardia, "Simultaneous stopped-flow determination of paracetamol, acetylsalicylic acid and caffeine in pharmaceutical formulations by Fourier transform infrared spectrometry with partial leastsquares data treatment," Analyst, vol. 121, no. 12, pp. 19351938, 1996.

[39] H. Ibrahim, A. Boyer, J. Bouajila, F. Couderc, and F. Nepveu, "Determination of non-steroidal anti-inflammatory drugs in pharmaceuticals and human serum by dual-mode gradient HPLC and fluorescence detection," Journal of Chromatography B, vol. 857, no. 1, pp. 59-66, 2007.

[40] C. Wang, X. Hu, Z. Leng, G. Yang, and G. Jin, "Differential pulse voltammetry for determination of paracetamol at a pumice mixed carbon paste electrode," Analytical Letters, vol. 34, no. 15, pp. 2747-2759, 2001.

[41] A. Criado, S. Cárdenas, M. Gallego, and M. Valcárcel, “Continuous flow spectrophotometric determination of paracetamol 
in pharmaceuticals following continuous microwave assisted alkaline hydrolysis," Talanta, vol. 53, no. 2, pp. 417-423, 2000.

[42] F. S. Felix, C. M. A. Brett, and L. Angnes, "Carbon film resistor electrode for amperometric determination of acetaminophen in pharmaceutical formulations," Journal of Pharmaceutical and Biomedical Analysis, vol. 43, no. 5, pp. 1622-1627, 2007.

[43] E. P. Medeiros, S. L. Castro, F. M. Formiga, S. R. B. Santos, M. C. U. Araujo, and V. B. Nascimento, "A flow injection method for biamperometric determination of dipyrone in pharmaceuticals," Microchemical Journal, vol. 78, no. 1, pp. 91-96, 2004. 


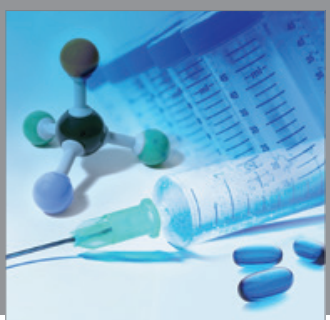

International Journal of

Medicinal Chemistry

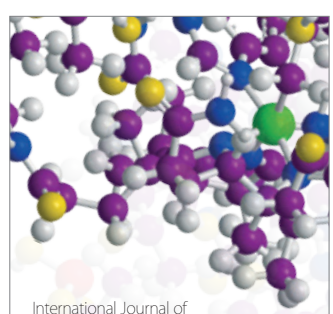

Carbohydrate Chemistry

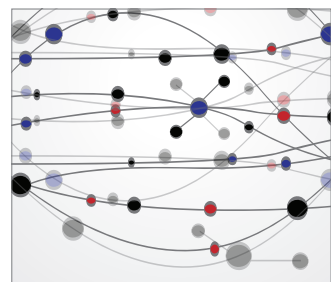

The Scientific World Journal
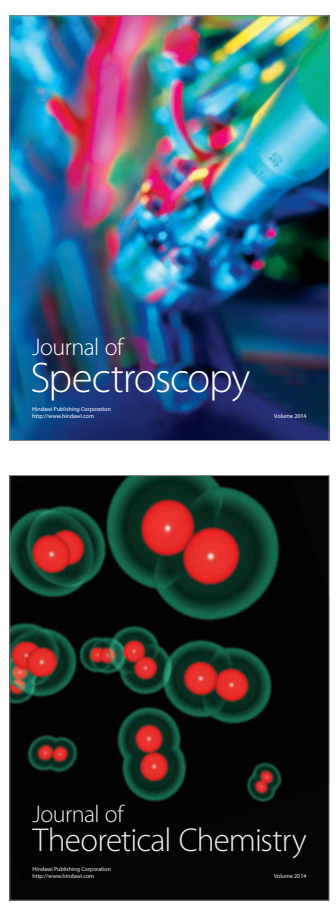
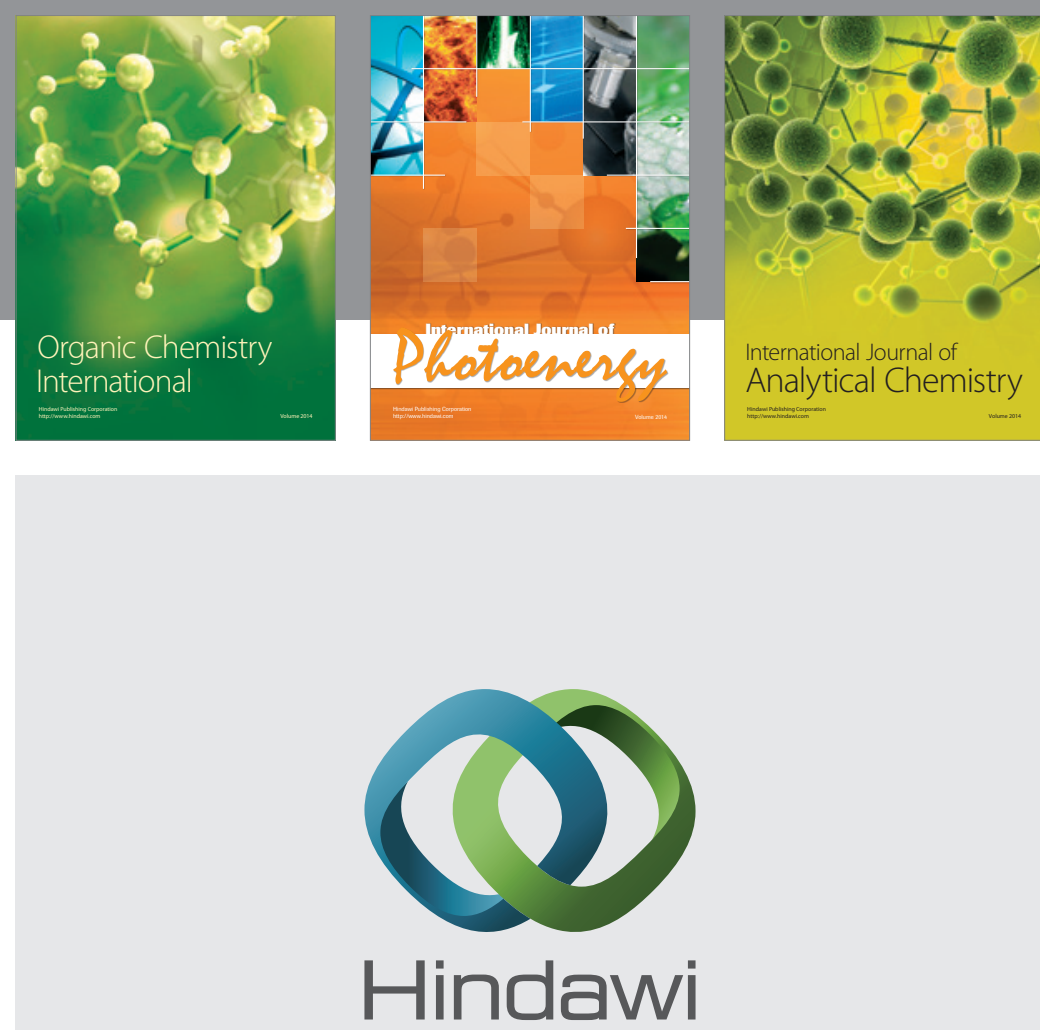

Submit your manuscripts at

http://www.hindawi.com
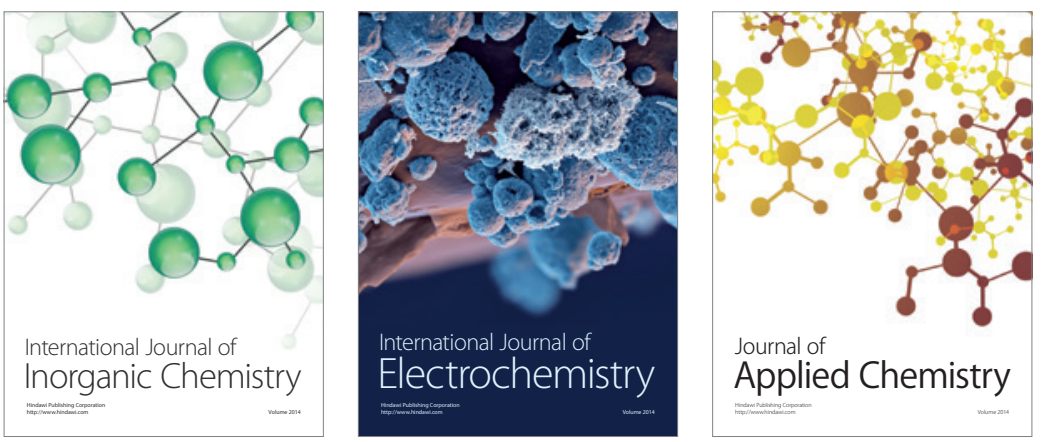

Journal of

Applied Chemistry
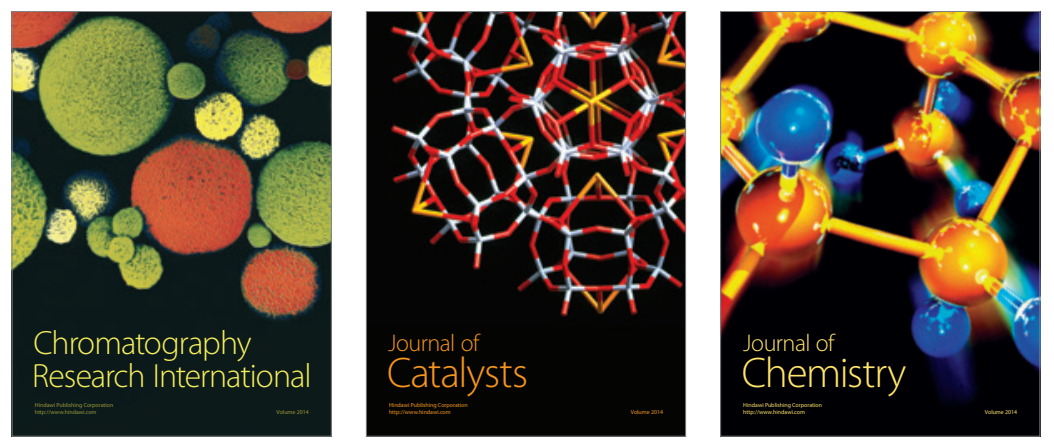
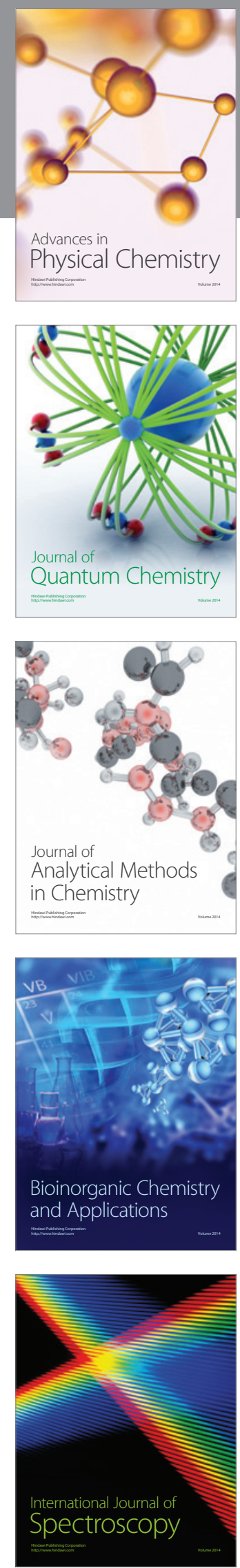